\section{Introduction to the}

\section{process of research: A focus on oncology nursing research}

\author{
By Margaret I. Fitch
}

\begin{abstract}
Nurses are expected to be involved with research, as part of their daily practice. Many, however, have not had the opportunity to learn about research or the research process. This article is an introduction to research for nurses working in oncology who have not had the opportunity to learn about the research process formally. Oncology mursing research examples are used to illustrate the research process. The intent of the article is to offer a user-friendly vehicle for oncology nurses to gain comfort with some of the terminology and concepts used in research. The content was organized on the basis of questions staff nurses have posed about research methods in oncology nursing
\end{abstract}

\section{Introduction}

With increasing frequency, nurses are expected to be involved in research as part of their daily practice. Many nurses, however, have not had the opportunity to learn about research and the research process. As a result, the expectation that they are reading research articles and utilizing research findings in their daily practice feels overwhelming. Attending a research presentation is not necessarily the choice of many clinicians and, when forced to do so, many perceive there is little relevance in the presentation content for their practice. The language of research is frequently cited by staff nurses as a barrier to appreciating its value for the practice setting.

This article was written as an introduction to the process of research for oncology nurses who have not had an opportunity to learn about it formally. Using examples of oncology nursing research, the research process and some of its terminology will be described. The intent of the article is to help oncology nurses gain comfort with the words and expectations of the research process so that reading research articles and listening to research presentations can be more meaningful. Ultimately, such behaviours will contribute to achieving research-based oncology nursing practice.

Nurses make many decisions in the course of their daily practice. What are the priorities for the day? Who is at greatest risk for difficulty? What patient needs should be assessed? How should a specific need be assessed? What nursing diagnosis is most appropriate? What nursing intervention will be most helpful to the patient? What intervention will be least expensive? Which technique or approach is best for teaching a patient who will have to deal with this problem at home?

The decisions a nurse makes, Margaret I. Fitch

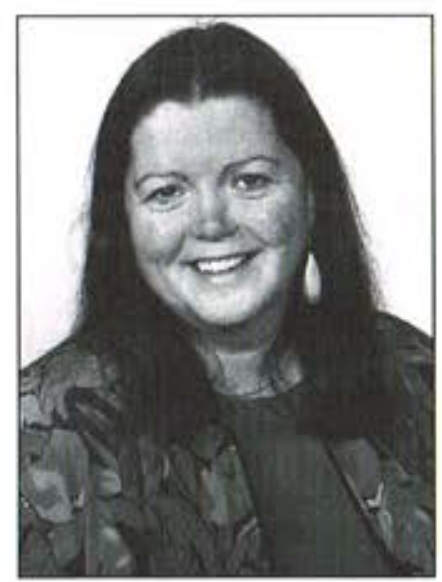

regardless of her role, have the potential to have a significant impact upon the patients, their family members, other nurses and the health care system. Nurses form a significant portion of the total number of health care professionals and have great potential for influencing patient care outcomes and the health care system.

To make good decisions, however, nurses must have good information, or what researchers call reliable and valid information. The information will only be as good as the methods used to collect it are sound. Sound data collection and analysis emerge from an understanding of research rigour and process. Nurses' ability to access and to make use of information gleaned from research depends in large measure on comfort in reading research reports and in critically analyzing the work. It can be difficult to gain that comfort when the research reports are not written in user-friendly terms, do not appear in clinical practice journals, and may not always be a primary focus for speciality practice conferences. Also, when carrying busy clinical workloads, finding the time to learn about the process of research can be a challenge.

This paper is written as a user-friendly introduction to research. It is aimed at oncology nurses who want to increase their comfort with some of the terminology and concepts (ideas) about research. It provides an overview of research, summarized from a wide range of resources, which can be read quickly. The content is organized in response to questions staff nurses have asked the author in workshops, courses and research interest groups. Hopefully, the introduction will be a stimulus to pursue the additional readings cited in the article.

\title{
Research as a way of knowing
}

There are different ways of knowing about the world (eg, intuition, trial and error, authority, custom, deduction and research). Research has characteristics over and above the other ways of knowing, in that it has built in a system of checks and balances that reduce the likelihood of chance or bias influencing the findings.

Ultimately, research endeavours are attempts to increase the understanding of the world and the influences in it. The tradition of scientific investigation has emerged from a long line of individuals who wanted to understand the connections between causes and effects or between actions and outcomes. That understanding grows as research studies build from exploring phenomena, to explaining relationships between and among phenomena, to predicting future events.

\section{INTRODUCTION AU PROCESSUS DE RECHERCHE - ACCENT SUR LA RECHERCHE INFIRMIËRE EN ONCOLOGIE}

\section{ABRÉGÉ}

Les infirmières sont supposées consacrer une partie de leurs activités quotidiennes à la recherche. Toutefois, nombreuses sont celles qui n'ont jamais eu l'occasion de se familiariser avec la recherche ou le processus de recherche. La présente communication se veut être une introduction à la recherche pour les infirmières qui oeuvrent en oncologie et qui n'ont jamais eu la possibilité d'apprendre quoi que ce soit sur le processus de recherche. $\mathrm{Ce}$ dernier est illustré à l'aide d'exemples de recherches infirmières en oncologie. Le but de cette presentation est de fournir aux infirmières en oncologie un instrument qui leur permettra de se familiariser avec quelques-uns des termes et des concepts employés en recherche. Le contenu a été organisé en fonction des questions posées par des infirmières de chevet sur les méthodes de recherche en soins infirmiers oncologiques.

Margaret I. Fitch, RN, PhD, is head division of oncology nursing and oncology nurse researcher at Toronto-Sunnybrook Regional Cancer Centre, Toronto, Ontario. 
The main goal of research in a practice profession like nursing is to provide clinicians with the knowledge required for patients to receive safe, quality care. Clinicians need to be able to predict that if they perform a certain action there will be a specific result. Information is needed that helps clarify the link between what clinicians do and what the outcomes will be for patients.

\section{The research process}

The research process is conceptualized as a series of steps. Different authors describe the research process using different numbers of steps. A variety of excellent basic research texts outline the steps in detail (see Table One) and the reader is encouraged to refer to one of these texts for detailed information. Although different steps have been used to describe the research process, the essential approach is the same: A problem is identified and an answer is sought. For the purposes of this article, the research process will be discussed in six steps:

1) identify the problem

2) review the literature

3) design the study

4) collect the data

5) analyse the data

6) communicate the results.

\section{Step 1: Identify the problem}

The first step in the research process is identifying the problem to be investigated. This involves selecting a research focus, articulating the research problem and pinpointing a specific purpose for the investigation. The research focus is the broad area of interest an investigator holds (eg, chronic illness, women's health, coping with cancer, family dynamics, pain management, health promotion). The research problem is an issue or

\section{Example A: Problems oncology nurse} investigators have studied include:

- What are the information needs of lung cancer patients after surgery? (Galloway, et al, 1993)

- What is the quality of life of long-term survivors of bone marrow transplantation? (Belec, 1992)

- What is the coping burden of family members caring for patients receiving chemotherapy? (Carey et al, 1991)

- Does music reduce cancer-related pain? (Beck, 1992)

- How does nutrition status affect the development of pressure sores in elderly patients with cancer? (Waltman, 1991)

- Which dressing is better for long-term central catheters in patients undergoing bone marrow transplantation - transparent adherent dressings or dry sterile gauze dressings? (Shivan, 1991)

- What is the experience of families having a member with advanced cancer who is receiving palliative care either at home or in the hospital? (Davies, Reimer \& Martens, 1990)

\section{Table One: Introductory nursing research} textbooks for further study

Burns, N. and Grove, S. Understanding Nursing Research. Toronto: Saunders, 1995.

La Biondo-Wood, G. and Haber, J. Nursing Research - Methods, Critical Appraisal and Utilization. Toronto: Mosby, 1990:*

Nieswiadomy, R. Foundations of Nursing Research. Norwalk, CT: Appleton and Lange, 1987.

Polit, D. and Hungler, B. Nursing Research: Principles and Methods. (4th Ed.) Philadelphia: Lippincott, 1991.*

Woods, N. and Catanzaro, M. Nursing Research, Theory and Practice. St. Louis: Mosby, 1988.

* Contains good introductory statistics chapters. concem for which an answer is sought or a solution is to be described, explained or predicted (See Example A). The research purpose is the specific aim for the study.

Research problems are often identified when practitioners notice that an observation they have made does not quite match with what they already know ( $\mathrm{eg}$, one patient recovers after surgery more quickly than the rest of the patients; or some patients seem to have more difficulty than most in coping with isolation). Such observations may stimulate a nurse to think about why the observation was made, whether it could happen again or whether it was a significant event. Research problems may also be identified when a nurse notices that something has been a repetitive problem, she believes something should be done differently or she observes a gap in service provision. When a problem has been identified, it is considered appropriate for research attention if it meets criteria such as the following:

1. the problem occurs often/is repetitive;

2. the problem is severe or potentially fatal;

3. the problem is amenable to intervention;

4. the problem creates costs which are too high for people who experience the problem or for the health care system;

5 . the problem represents long-term practices and/or policies which need accurate information to aid in decision-making;

6. the problem represents a neglected area of study.

Problems for research can be identified in various ways: Through observation in practice, reading, talking with colleagues and listening to patients. The clinical area is filled with researchable problems just waiting for a curious nurse to discover them!

The purpose and specific research questions for investigation can be formulated once the research problem has been identified. The purpose pinpoints the specific aim or goal of the study. It may be specified further through research questions or objectives (see Examples B1 and B2). These questions or objectives identify specific steps or tasks that,

\section{Example B1}

Purpose: To explore the validity of teaching older women the practice of BSE using the method of return demonstration (Maddox, 1991).

\section{Research questions:}

1) Does the teaching method of return demonstration influence an older woman's level of confidence in her ability to perform BSE?

2) Does the teaching method of return demonstration influence an older woman's accuracy in locating abnormalities within breast models?

3) Does the teaching method of a three-month follow-up return demonstration influence an older woman's level of confidence in her ability to perform BSE?

4) Does the teaching method of a three-month follow-up return demonstration influence an older woman's frequency of performing BSE?

5) Does the teaching method of a three-month follow-up return demonstration influence an older woman's accuracy of locating abnormalities within breast models?

\section{Example B2}

Purpose: To explore the informational needs, attitudes toward information about and participation in medical care and treatment, and emotional states of patients with cancer receiving brachytherapy (Brandt, 1991).

Research objectives:

1) To determine the types of information needed by patients with cancer receiving interstitial or intracavitary brachytherapy;

2) To determine the degree to which these patients prefer to become informed about and to participate in their medical care;

3) To determine the relationships among informational needs, participation preference, age, education, stage of disease and emotional state. 
when completed, will fulfil the study aim (purpose). The purpose and research questions make clear who will be studied (target group, population) and what topics will be considered. It is critical that the purpose be clearly stated, for it is the basis for the research study directions. If the purpose is not clearly stated, the study can easily become sidetracked.

Finally, the last aspect of identifying a problem for study concerns identifying the potential benefits of conducting the study. The potential benefits need to be stated clearly at the onset. Will nursing practice be more effective or patient care improved? Will costs be reduced? What can be done with the information that will be gathered? Or what will happen if this problem is ignored?

\section{Step 2: Review the literature}

The second step in the research process is reviewing the literature. This step is needed to understand the state of the knowledge or what is known about the problem selected for study. It is important to build upon what other investigators have already done and not repeat work needlessly. By reviewing information about what others have done in the field, it becomes clear how significant the identified problem really is and how any new project ought to proceed.

The literature review helps focus the particular direction of the proposed investigation. In some instances the literature review reveals that the particular question posed for study has already been answered or answered in part. For example, in the area of pain management, we have a great deal of knowledge about how to help people who are in pain, but we do not seem to understand why nurses and doctors do not utilize this knowledge in daily practice. A study focused on the latter concern might be more useful than replicating a study that identifies pain levels in patients with cancer.

In other instances, the literature review may reveal that there is insufficient knowledge available to work on the questions posed for study. The study may have to begin at a more rudimentary stage than originally thought. For example, a nurse may wish to determine the influence of hope on how well cancer patients cope. In her literature review, she may find there is no instrument or tool that measures hope and she must begin her work by developing a way to measure the phenomenon of hope.

The literature review, in addition to providing assistance in setting the direction for a research project, can also be useful in other ways. Reading through the existing knowledge on a topic provides ideas about:

- how terms are defined

- appropriate theoretical frameworks (conceptual ideas) for the topic area

- methods (procedures) that could be appropriate to study the topic

- how successful a study of the topic might be

- who the experts in the field are, should you wish to contact them.

A key resource in conducting the literature review is the librarian.

\section{Example C: Examples of qualitative studies}

Pierce (1993) reported a qualitative study that described the unaided decision-making process of women facing treatment for early stage breast cancer. Forty-eight women consented to an open-ended interview where they were asked to "think out loud" about their decision regarding treatment. The analysis of the audiotaped interviews allowed identification of concepts regarding decision-making that could form the conceptual framework for further investigation.

Berry (1993) reported a qualitative study that documented the experience of returning to work following a cancer diagnosis. Twelve individuals with genitourinary cancer consented to two face-to-face interviews six to 16 weeks apart to talk about the experiences in returning to work following their diagnosis. The study results described the process and issues experienced by the individuals.
The librarian can provide invaluable assistance by identifying resource materials and computerized search capabilities in the library.

\section{Step 3: Design the study}

Once the purpose of a study has been established and the literature review reveals that an investigation needs to be conducted, the next challenge is the design of the procedures or study methods. Designing a study involves planning all the procedural details regarding what variables will be studied, who will be included, how potential participants will be contacted, how data will be collected and how data will be analyzed. The research design must be a logical extension from the research problem and study purpose.

Within nursing, there are two fundamental approaches to research design: qualitative and quantitative. The choice to use one approach or another is dependent upon the nature of the problem being studied, the purpose of the study and the type of information being sought. Qualitative approaches involve broadly stated questions about human experiences studied through sustained contact with people in their natural environment. Rich descriptive data are generated that help us understand people's experiences. There are various qualitative methods (eg, ethnography, grounded theory, phenomenology) to help us determine patterns in relationships and understand ways in which people make sense of their worlds (see Example C).

Quantitative research designs quantify or measure phenomena in numerical ways (see Example D). The numerical data are manipulated through statistical procedures to describe phenomena or to identify relationships between them. The many quantitative methods differ in the amount of control exerted over the study conditions. A true experimental study is considered to have the highest degree of control. Control refers to the steps, measures or procedures a researcher utilizes to hold the conditions of the investigations uniform. The degree of control that exists in a study design influences how much confidence can be placed in the study results. Inappropriate attention to issues of control or uniformity run the risk of bias being introduced into the study and the study data may not be believed or seen as valid. For example, if comparing two patient groups in terms of pain management, it would be important to select the individuals for both groups in the same way and gather data in the same manner in both groups.

Ultimately, scientific investigations seek to establish evidence of cause-effect relationships. An experimental design provides the strongest evidence for a cause-effect relationship because the properties of this design (i.e. randomization, control, manipulation) help to eliminate other possible explanations (alternate explanations) for the study findings. In an experimental study, the investigator randomly assigns patients to study groups called experimental and control groups. Random assignment means the selected subjects have an equal chance of being put in a control group or an experimental group. The investigator maintains the same study procedures for all study groups and only changes or manipulates the variable under investigation in the experimental group. A clinical trial is an experimental design.

Sometimes, all the conditions for a true experimental design cannot be met. It may not be possible to randomly assign subjects or to find an appropriate control group. In these circumstances, a quasi-experimental design is applied. In these instances, opportunities for inconsistencies may increase and thus the likelihood of bias. Planning for the study must take the potential sources of bias into account and understand how they might influence the results.

In many instances, nursing is not yet ready for experimental studies. The understanding of some nursing-related phenomenon is still lacking or it may be too difficult to control specific variables (i.e. characteristics of the environment or the context). Other designs must be applied initially (eg, quasi-experimental, correlational, descriptive) to enhance the understanding of variables, their measurement and their relatedness.

There are specific elements that must be identified during the designing phase regardless of the type of design selected for a particular 
study. These elements include:

- who will be studied (population, target group)

- specific characteristics about the potential target group (inclusion and/or exclusion criteria; eligibility criteria)

- how potential participants will be identified, approached, told about the study and agree to participate

- what data will be collected

- how, when and where the data will be collected

- what, if any, specific instruments or tools will be used to collect data

- how the data will be analyzed

- steps that will be taken to ensure privacy, confidentiality, etc.

- if an intervention is used, specific detail about what was done.

These elements must be described clearly in a research report. The section regarding design will be labelled methods, methodology or procedures and may include subsections that describe the sample, setting, instruments and data collection procedures. In many instances, some of the specific detail regarding the procedures may not appear in a journal article. As a result, if someone wishes to fully understand what was done or wishes to replicate (repeat) a particular study, she or he may have to contact the original investigator to discuss the procedural details.

\section{Step 4: Collect the data}

There are many ways to collect information about the topics or phenomena that interest nurses. From a research perspective, the critical aspect to consider is that the data collection techniques used are objective and systematic. "Objective" means that the data are not influenced or changed by anyone who collects the information. "Systematic" means the data must be collected in the same way by everyone who is involved in the data collection procedures.

There are five main data collection techniques used by nurses. Biological and physical measurement techniques are used to measure variables such as blood pressure, pulse, temperature, weight or blood glucose levels. Interesting examples of such variables can be found in Lindsey's work (1993) regarding lung cancer patients and their weight loss, nutritional status and functional levels. Observational techniques are used to identify how people behave under certain conditions (eg, nurse-patient communication, behaviour during isolation). Frequently, a research study needs information from individuals about themselves that only the individual would know (eg, attitudes, perceptions, beliefs). Nurses need to ask research participants questions to learn about variables such as attitudes, beliefs, knowledge or perceptions. The data may be gathered through an interview or by having the research participants complete a questionnaire. The questions may be closed (the person selects from answers provided by the investigator) or open-ended (the person does not have responses provided by the investigator from which to select). Studies reported by Champion (1993) about breast screening practice, Mock (1993) regarding body image and Mickley et al (1992) regarding spirituality used questionnaires to gather data. Studies by Vachon et al (1991) to identify patient needs used an interview approach. Finally, records of available data are used to gather research information (eg, patients' charts). Kern et al (1992) reported using charts to review variables involved in instituting do not resuscitate orders. Bruera et al (1993) used charts to assess the effectiveness of the Edmonton Injector for administering parenteral opioids for cancer pain.

Each of the data collection techniques has advantages and disadvantages which must be considered by an investigator in choosing the appropriate technique for a particular study. For example, all else being equal, a face-to-face interview approach tends to provide richer data and have a higher participation rate as compared to a written questionnaire. Also, an interview approach could include individuals who are blind, those who cannot read and children who might not be able to complete a written questionnaire. On the other hand, a questionnaire might be less expensive and less time-consuming to administer and incorporate a larger number of people than an interview approach.

A critical issue in using data collecting techniques is the reliability and validity of the data collection instrument or tool. Reliability refers to the consistency in the performance of an instrument (i.e. will you obtain the same results in similar situations?). Validity refers to whether an instrument does what it's supposed to do (i.e. if the instrument is

\section{Example D: Example of quantitative studies}

\section{Example study experimental:}

Cimprich (1993) reported an experimental study to test the effect of a nursing intervention aimed toward maintaining or restoring attentional capacity in 32 women during the three months after surgery for localized (State I or II) breast cancer. The capacity to direct attention, to focus or concentrate, is critical in dealing with a major illness. Facing an illness such as cancer, with its many demands, can weaken an individual's capacity to attend.

The intervention was designed to minimize or prevent attentional fatigue. Attentional capacity was assessed using subjective and objective measures at four points in time $(3,18,60$, 90 days post-operatively). After the final observation time, women were randomly assigned to receive the intervention ( 16 women) or not receive the intervention ( 16 women). Specifically, the findings revealed the women who received the intervention showed significant improvement in their attentional capacity over the four time periods. Women who did not receive the intervention had inconsistent performance patterns.

\section{Example study quasi-experimental:}

McGill and Paul (1993) report a quasi-experimental study of functional status and hope in elderly people with and without cancer. The with cancer group was a convenience sample of 86 patients 65 years of age and older attending an oncology clinic. The without cancer group consisted of 88 elderly people in the community who perceived their health as good or excellent and who had never been diagnosed with cancer. The results of the study indicated that declining physical health is a threat to hope and that

lower socioeconomic status may be a threat to hope; however, age, gender or a diagnosis of cancer are not.

\section{Example study correlational:}

Taylor (1993) conducted a correlational, cross-sectional study to determine what factors were associated with a sense of meaning in life among people with recurrent cancer. A convenience sample of 74 subjects completed six survey instruments that measured purpose in life, symptom distress, enforced social dependency, psychosocial adjustment to illness, search for meaning and demographic/illness variables. Overall, the findings of the study demonstrated that the sense of meaning is integrally associated with physical and psychosocial effects of illness and suggest that oncology nurses must understand how to care for those who search for meaning.

\section{Example study descriptive:}

McGuire et al (1993) report a descriptive study conducted to document the incidence, onset, duration, severity and other relevant characteristics of mucositis and pain in patients undergoing bone marrow transplantation. Forty-seven patients undergoing allogenic and autologous BMT were followed each day, from nine days prior to BMT through 21 days after BMT. Overall, $89 \%$ of the patients developed mucositis, which, on average, began three days after transplant and lasted 9.5 days. Eighty-six per cent of the patients reported pain that began, on average, 4.5 days after transplant and lasted 6.5 days. 
supposed to measure anxiety or depression, it truly measures that phenomenon). Detailed accounts of these and other psychometric properties can be found in texts by Waltz et al (1984), Frank-Stromberg (1992), Streiner (1989) and Nunnally (1978). Articles describing how instruments are designed and evaluated for reliability and validity have been written by Lovette for bone marrow transplantation acuity (1993), Nowotny (1989) for assessing hope and Frank-Stromberg (1989) for assessing reaction to a cancer diagnosis.

One other critical consideration in data collection concerns the ethics of conducting research with humans. Whenever a research study involves human beings, it is imperative the study plans are reviewed by an institutional research ethics board or committee. The review is conducted to evaluate the balance of potential harm to individuals from participating in the study and the potential benefits of what can be learned from the study. An investigator must describe the risks and benefits of the study in the research planning document and to any potential patient or family member. The procedures for discussing the study with a potential participant must be clearly outlined and consent form signed by each individual who agrees to participate in a research study. The potential participant must be very clear about the following points: 1) his or her participation is absolutely voluntary, 2) whether an individual decides to participate or not has no bearing on their care and, 3) even if they decide to participate at the onset, the individual must feel free to withdraw (if they wish) at any future time. As a patient advocate, nurses often help patients understand these ideas.

Finally, during data collection, care needs to be taken to ensure the data are kept confidential. Privacy should be provided for any data collection session and sensitivity used to gather information regarding sensitive topics.

\section{Step 5: Analyze the data}

Once data have been collected, an investigator is faced with the challenge of pulling all the many discrete pieces of information together into some kind of meaningful picture. In quantitative studies, statistical procedures are applied to accomplish this task. With qualitative studies, content and theme analysis are fundamental approaches.

Statistical approaches are classified as descriptive and inferential. Descriptive statistics are used to describe and summarize data. They are used to reduce the data to manageable terms and help us see patterns in the data. The following is an example of descriptive statistics that could be reported: The study participants included 25 women and 30 men with an average age of 55.5 years. Descriptive techniques include measures of central tendency (i.e. mean or average, median, mode) and measures of variability (i.e. range, standard deviation, modal percentage) and some correlational techniques (i.e. scatter plots). These statistics provide an understanding of how close together or how spread out the data are.

Descriptive statistics also help in the process of thinking about how relevant the data are for one's own practice purposes. It would be inappropriate to draw conclusions for use with a practice population if the study population had a significantly different age range or educational level. Similarly, if one report concerned study participants who scored between 10 and 20 on a questionnaire, and a second report concerned study participants who scored between 80 and 95 on the same questionnaire, it is appropriate to question whether one group is different in some way than the other. Hence, the descriptive statistics concerning the sample in a study is a particularly important aspect in reading a research report. Close attention to the characteristics of the study sample will help to indicate whether the study might apply to other groups or whether the study participants are like the patients in one's own practice.

Inferential statistics are used to estimate how reliably predictions can be made about a population from the data in a study sample. They are used to draw conclusions about larger groups from the study group (sample). Inferential statistics combine mathematical and logical processes to test ideas about similarities and differences in the observations seen in studies.
There are many statistical maneuvers (eg, Students' t-test, Chi-Square) with specific conditions under which each statistical maneuver is performed. The appropriateness of the statistics employed in any study relate to the problem or research question, design, methods and type of data used in the study. Clearly, therefore, correct and incorrect applications exist. Often statistical analysis is an area where consultation is helpful.

Additionally, it is important to know how much confidence we can place in the observations we see. If a study observation is likely to be made one out of 10 times simply by chance $(\mathrm{P}=0.10)$, we cannot place much faith in that observation. On the other hand, if an observation is likely to occur only one out of 100 times because of chance $(\mathrm{P}=0.01)$, then we can place more confidence in the idea that this observation may be significant. In other words, chance did not have a large role to play; the likelihood of chance influencing the observed result is small. P values give us an indication of how much of a role chance had to play in any particular study observation. Traditionally, in health research, we would not accept a $\mathrm{P}$ value greater than 0.05 as meaningful statistically.

The approach to data analysis for qualitative studies involves finding patterns and meaning in word data. This type of analysis demands the same attention to detail that quantitative analysis demands. The analysis will produce a rich description of events or experiences. Such description provides the opportunity to gather new insight or perspective about a phenomenon, to find better ways of talking about the phenomenon with patients or clients and to design new conceptual models for future research. There are various methods for approaching such analyses and excellent references exist that provide detailed explanation of the procedures (Leininger, 1985; Munhall \& Oiler, 1986). Work by Coward (1990) regarding self-transcendence in breast cancer, work by Bottorff (1993) regarding the use of touch with cancer patients, work by Manson et al (1993) regarding thoughts and images during chemotherapy and work by Lauver and Angerame (1993) regarding women's expectations about seeking care for breast symptoms offer good examples of different qualitative analyses.

\section{Step 6: Communicate the results}

The last and equally important step in the research process is communicating the results of the study. Communicating the results means that what has been learned during the study is shared with others. Depending upon the actual study, others may wish to use the findings in their daily practice, in the development of their policy and procedures or to build a new study. The new study may try to build directly upon the findings and extend what knowledge is known, it may try to replicate or repeat the study, or it may try to overcome some of the limitations of the original work. None of this can happen if the study results are not communicated.

Investigators use various avenues to communicate study results including publishing papers or articles in journals, speaking at meetings or conferences, and presenting posters at conferences. In most instances, the investigator must take the initiative and send the article to a journal or answer a "call for abstracts" from a conference. Both activities require skill in writing clearly and writing for the audience who will be reading the material. For many nurses, these skills need to be learned and honed through practice. It is beyond the scope of this article to deal in more depth with the skills but there are good resources available (Holm \& Llewellyn, 1986; Longman, 1986; Morra, 1984; Tornquist, 1986; Sheridan \& Dowdny, 1986).

An important aspect concerning the communication of research findings concerns the role of the consumer of research, the nurse. The consumer has a role in commenting on the research, in asking questions about the methods and in reviewing the findings. These are critical activities if researchers are to translate their work into understandable ideas and clinically useful material. The dialogue between clinicians and researchers must be enhanced if we are to achieve research-based practice. There are publications available that can help in developing the skills and comfort in reading a research paper or listening to a research presentation (Davies and Logan, 1983; Duffy, 1985). 


\section{Conclusion}

This article was written as an introduction to the research process. It is for those who have not had an opportunity to learn about research formally and want an introduction to it. The content highlights key aspects of the research process and explains fundamental terms. 1 hope it will help readers feel more comfortable when reading research articles and listening to research presentations and encourage them to pursue more detailed study in the available texts regarding nursing research.

\section{References}

Beck, S.L. (1991). The therapeutic use of music for cancer-related pain. Oncology Nursing Forum, 18(8), 1327-1337.

Belec, R.H. (1992). Quality of life: perceptions of long term survivors of bone marrow transplantation. Oncology Nursing Forum, 19, 31-37.

Berry, D.L. (1993). Return to work experiences of people with cancer. Oncology Nursing Forum, 20(6), 905-911.

Botteroff, J.L. (1993). The use and meaning of touch in caring for patients with cancer. Oncology Nursing Forum, 20(10), 1531-1538.

Brandt, B. (1991). Informational needs and selected variables in patients receiving brachytherapy. Oncology Nursing Forum, 18(7), 1221-1227.

Bruera, E., Velasco-Leiva, A., Spachynski, K., Fainsinger, R., Miller, M.J. and MacEachern, T. (1993). Use of the Edmonton Injector for parenteral opioid management of cancer pain: a study of 100 consecutive patients. Journal of Pain and Symptom Management, 8(8), 525-528.

Carey, P.J., Oberst, M.T., McCubbin, M.A. and Hughes, S.H. (1991). Appraisal and caregiving burden in family members caring for patients receiving chemotherapy. Oncology Nursing Forum, 18(8), 1341-48.

Champion, V.L. (1993). Instrument refinement for breast cancer screening behaviours. Nursing Research, 42, 139-143.

Coward, D.D. (1990). The lived experience of self-transcendence in women with advanced breast cancer. Nursing Science Quarterly, 3(4), 162-169.

Davies, B. and Logan, J. (1993). Reading research. Ottawa: Canadian Nurses Foundation.

Davies, B., Reimer, J.C., and Martens, N. (1990). Families in supportive care-part I: the transition of fading away: the nature of the transition. Journal of Palliative Care, 6(3), 12-20.

Duffy, M.E. (1985). A research appraisal checklist for evaluating nursing research reports. Nursing and Health Care, (Dec.) 539-547.

Frank-Stromberg, M. (1992). Instruments for clinical nursing research. Boston: Jones and Bartlett Publishers.

Frank-Stromberg, M. (1989). Reaction to the diagnosis of cancer questionnaire: development and psychometric evaluation. Nursing Research 38(6), 364-369.

Galloway, S.G., Bubela, N., McKibbon, A., McCay, E. and Ross, E. (1993). Perceived information needs and affect of symptoms on activities after surgery for lung cancer. Canadian Oncology Nursing Journal, 3(3), 116-119.

Holm, K. and Llewellyn, J.G. (1986). Communicating research. In Nursing Research for Nursing Practice. Holm, K. and Llewellyn (eds). Toronto: W.B. Saunders.

Kern, D., Kettner, P., and Albrizio, M. (1992). An exploration of the variables involved when instituting a do-not-resuscitate order for patients undergoing bone marrow transplantation. Oncology Nursing Forum, 19(4), 635-640.

Lauver, D. and Angerame, M. (1993). Women's expectations about seeking care for breast cancer symptoms. Oncology Nursing Forum, 20(3), 379-525.

Leininger, M.M. (1985). Qualitative research methods in nursing. New York: Grune \& Stratton.
Lindsey, A., Larson, P.J., Sarna, L. and Brown, J.K. (1993). The lung cancer experience: nutritional intake, weight, functional status and other factors - comparison of variables and findings across three studies. Oncology Nursing Forum, 20(3), 465-493.

Longman, A.J. (1986). Preparing a speech for publication. Oncology Nursing Forum, 13(4), 71-73.

Lovett, R.B. and McMillan, S.C. (1993). Validity and reliability of a bone marrow transplant acuity tool. Oncology Nursing Forum, 20(9), 1385-1392.

Maddox, M.A. The practice of breast self examination among older women. Oncology Nursing Forum 18(8), 1367-1371.

Manson, H., Manderino, M.A. Johnson, M.H. (1993). Chemotherapy: thoughts and images of patients with cancer. Oncology Nursing Forum, 20(3), 527-531.

McGill, J.S. and Paul, P.B. (1993). Functional status and hope in elderly people with and without cancer. Oncology Nursing Forum, 20(8), 1207-1213.

McGuire, D.B., Altomonte, V., Peterson, D.E., Wingard, J.R., Jones, R.J. and Grochow, L.B. (1993). Patterns in mucocitis and pain in patients receiving preparative chemotherapy and bone marrow transplantation. Oncology Nursing Forum, 20(10), 1493-1502.

Mickley, J.R., Soeken, K. and Belcher, A. (1992). Spiritual well-being, religiousness and hope among women with breast cancer. Image, 24(4), 267-272.

Mock, V. (1993). Body image in women treated for breast cancer. Nursing Research, 42, 153-157.

Morra, M.E. (1984). How to plan and carry out your poster session. Oncology Nursing Forum, 11(2), 52-57.

Munhall, P.L. and Oiler, C.J.(1986). Nursing research - a qualitative perspective. Norwalk: Appleton-Century-Crofts.

Nowotny, M.L. (1989). Assessment of hope in patients with cancer: development of an instrument. Oncology Nursing Forum 16(1), 57-61.

Nunnally, J.C. (1978). Psychometric theory. Toronto: McGraw-Hill. Pierce, P.F. (1993). Deciding on breast cancer treatment: a description of decision behaviour. Nursing Research, 42 22-27.

Sheridan, D.R. and Dowdney, D.L. (1986). How to write and publish articles in nursing. New York: Springer.

Shivan, J.C., McGuire, D., Freedman, S., Sharkazy, E., Bosserman, G., Larson, E. and Grouleff, P.A. (1991). Comparison of transparent adherent and dry sterile gauze dressings for long-term central catheters in patients undergoing bone marrow transplant. Oncology Nursing Forum, 18(8), 1349-1356.

Streiner, D.L. and Norman, G.R. (1989). Health measurement scales: a practical guide to their development and use. Oxford: Oxford University Press, 1989.

Taylor, E.J. (1993). Factors associated with meaning in life among people with recurrent cancer. Oncology Nursing Forum, 20(9), 1399-1405.

Tornquist, Elizabeth M. (1996) From proposal to publication. Don Mills, Ontario: Addison-Wesley.

Vachon, M.L.S., Lancee, W.J., Ghadirian, P., Adair, W.K., and Conway, B. (1991). Final report on the needs of persons living with cancer in Quebec. Toronto: Canadian Cancer Society.

Waltman, N.L., Bergstrom, N., Armstrong, N., Norvell, K. and Braden, B. (1991). Nutritional status, pressure sores and mortality in elderly patients with cancer. Oncology Nursing Forum, 18(5), 867-873.

Waltz, C., Strickland, O.L. and Lenz, E.R. (1984) Measurement in nursing research. Philadelphia: F.A. Davis. 